\title{
Knowledge and Practices of School Team Members Regarding Injuries Prevention among Disabled Children
}

\section{Mona Mostafa Mohamed Elsharqawi ${ }^{1}$, Hanaa Abd-Elgawad Abd-Elmegeed ${ }^{2}$ and Doaa Sobhy Mohamed Elsayed ${ }^{3}$}

(1)Teacher in Nursing Institute, (2) Professor of Community Health Nursing, Faculty of Nursing, Benha University (3) Assist. Professor of Community Health Nursing, Faculty of Nursing, Benha University.

\begin{abstract}
Background: Injury is the most common health problems among disabled children and its prevention has received increased attention recently. The aim of the study: Was to assess knowledge and practices of school team members regarding injury prevention among disabled children .Research design: Descriptive analytical design was utilized to conduct this study. Setting: This study was conducted in three schools for disabled children in Al-fikria school for mental retardation students, Alamal School for deaf and dumb students, and Elnour School for blindness students. Sample: All team members in the selected schools (289 members) were included in the study. Tools: Data was collected by using two tools I): An interviewing questionnaire to assess a): Personal data of school team members. b): school team members ' knowledge about disability and injuries. c): Team members' practices as reported related to first aids of injuries. II): An observational checklist to assess environmental safety and sanitary conditions. Results: There were $78.2 \%$ of the school team members did not receive any training courses about first aid before, 53.6\% of the school team member had average knowledge about school injuries, $59.9 \%$ of the studied school team members had unsatisfactory practices towards the first aids of injuries and 100\% of schools environment were safe and sanitary. Conclusion: There were highly statistically significant relations between the team members' educational level and their total knowledge, also between the team members training courses and their total practices. Recommendations: Health education and training programs should be developed and implemented to upgrade school team members' knowledge and practices toward injury prevention to disabled children.
\end{abstract}

\section{Keywords: Disabled Children, School Team Members, Injury Prevention.}

\section{Introduction}

Disability refers to any impairment, activity limitations, or participation restrictions, or the outcome or result of a complex relationship between an individual's health condition and personal factors, and of the external factors that represent the circumstances in which the individual lives. Children with disabilities had more than double the rate of injury reported than children without disabilities. Almost one third of these injuries were due to fights, roughhousing, and assaults. Among all disabled children, those with orthopedic disabilities had the highest risk, with rates over 5 times that of children without disabilities (Allender et al., 2015).

Children are inherently more vulnerable to environmental hazards because their bodies are still developing. Substandard 
environmental conditions in schools, such as insufficient cleaning or inadequate ventilation, can cause serious health problems for children .Unintentional injuries historically referred to as accidents, san injury that is judged to have occurred without anyone intending that harm be done. Also, refers to any injury that result from unintended exposure to physical agents, including heat, mechanical energy, chemicals, or electricity (Fayed \& Darren, 2017).

Injuries are important health problem among school children in Egypt. They were the cause of significant morbidity and disability, important cause of school absence, and has significant burden on health facilities in Egypt. Special considerations for Injury Prevention are emphasized. Optimally, these initiatives would involve multidisciplinary approaches and target individuals, parents, health care providers, and community/local government leaders. Strategies need to be easily adaptable, so they can be modified to meet the language, culture and political needs of different communities (Banerji, 2015).

School team members are school manager, teachers, psychologists, nutritionists, social worker, night supervisors, security men, nurse and workers. School team member's knowledge, attitude and practice are relevant variables and are considered important factors in planning an educational program for accidents prevention so many accidents could be less serious if School team members know what to do as soon as accidents occur (New Mexico School Health Manual (NMSHM), 2015).

The community health nurse is an active participant in student medicine, physical, emotional, and mental health, preventative care, health and wellness education, hygiene education, first- aid, emergency response, medication management counseling, interventions, and the establishment of the health care plan. The nurse has the educational and clinical background needed to understand the issues of environmental health and advocate for a physically and emotionally healthy school community. Additionally, the school nurse is a vital member of the school team that leads change to advance health and collaborates with school staff members, parents and community members to keep students safe at school and healthy to learn (American Nurses Association, 2018).

\section{Significance of the study}

Children with disabilities had a significantly increased risk for injury. It is estimated that $10 \%$ of children globally suffer from some kind of disability, and most of whom live in low- and middle-income countries. Children with disabilities had more than doubled the rate of injury reported than children without disabilities (incidence density ratio [IDR] 2.3, 95\% CI, 2.2-2.5. Also found that children with disabilities had a significantly higher prevalence of injury than children without disabilities (10.2\% vs. 4.4\%; P, 0.001) ( Fayed\& Darren, 2017).

Recently, injury prevention among children with disabilities has received increased attention. Many researchers have reported that children who had a single disability had a significantly higher prevalence of injury than children without a disability (3.8\% vs. $2.5 \%$; $\mathrm{P}<.01)$.. However, previous studies are limited because they examine only one type of disability or they don't distinguished between types of disabilities were focused only on one setting 
and on one type of injuries. Injuries are important health problem among school children in Egypt. Injuries were the cause of significant morbidity, important cause of school absence, and has significant burden on health facilities in Egypt (Fekaris et al., 2017).

\section{Aim of the study}

This study aimed to assess school team members' knowledge and practice regarding injury prevention among disabled children

\section{Research questions}

1-What are the knowledge and practices of school team members regarding injuries prevention among disabled children?

2- What is the relation between personal data of school team members and their knowledge regarding injuries prevention among disabled children?

3- What is the relation between personal data of school team members and their practices regarding injuries prevention among disabled children?

4- What is the relation between the school team member's knowledge and practices of injuries prevention among disabled children?

\section{Subject and Methods \\ Research Design:}

A descriptive research design was utilized in this study to assess knowledge and practices of school team members regarding injuries prevention among disabled children.

\section{Setting:}

The study was conducted in three governmental schools for disabled children at Benha City. Namely:
Al-Fikria school for mental retardation students: This school serves mentally retarded students for boys and girls. Their age ranged from 6 to 18 years. These students had intelligence quotient (IQ) from 50 to $75 \%$ (mild mental retardation). School team members were 106 members.

Al-Amal school for deaf and dumb students: This school serves students with hearing and communication impairment for boys and girls. Their age ranged from 6 to 18 years. School team members were 101 members.

El-Nour school for blindness: This school serves students with vision impairment for boys and girls. Their age ranged from 6 to 18 years .School team members were 82 .

Sampling: Convenient sample of all school team members working in the previously mentioned setting (total number 289).

Tools of data collection: The data were collected using two tools

\section{First tool: An interviewing questionnaire:}

It was developed by the investigator and under supervisor staff based on reviewing related literature review and experts opinions, written in simple Arabic language. It compromised two main parts to assess the following:

Part I: Personal data of school team members: This part included seven items: (Age, sex, school name, educational level, marital status, years of experience and courses related first aids).

$\begin{array}{lrrr}\text { Part II: } & \text { Knowledge } & \text { of school team } \\ \text { members } & \text { regarding } & \text { disability } & \text { and } \\ \text { injuries:- } & & & \end{array}$


This part designed to assess school team members' knowledge: a-Knowledge about disability as (meaning, types and causes).

b- Knowledge about injuries as meaning, exposure to injuries, causes of injuries exposure, relation between injuries and type of disability, who was the most exposed to injuries, types of injuries and the source of school team members knowledge.

C-School team members' knowledge regarding causes, risks and preventive measures of school injuries which included:

-Falls: meaning, causes, complication and prevention.

-Wounds: meaning, causes, complication and prevention

-Burns: meaning, causes, complication and prevention.

-Poisoning: meaning, causes, complication and prevention.

-Electrical shock: meaning, causes, complication and prevention.

-Suffocation: meaning, causes, complication and prevention.

\section{Scoring system for knowledge:}

For each item, a complete correct answer was scored (2), incomplete correct answer was scored (1) and the don't know answer was scored (zero). For each question, the scores of all items were summed up and the total score for all items selected to knowledge which consisted of (34) items were (68) scores and categorized into three levels as follow: poor knowledge is $<50 \%$ ( $<34$ score), average knowledge is 50-70\% (34-48 score) and good knowledge is $>70 \%$ ( $>48$ score).
Part III: Reported practices of school team members regarding first aids of disabled children injuries:-

This part consisted of 8 closed ended questions developed by the investigator for assessing school team members' practices regarding first aid for disabled children injuries as (fractures- wounds - thermal burns - electrical shock - swallowing foreign body drowning - poisoning -suffocation by gases) as reported by school team members

Scoring system for practices, the score for each response was given as follows: (1) score for done and (0) score for not done. The total practice score was considered satisfactory if the score of total practices is $\geq 60 \%$ while considered unsatisfactory if it is $<60 \%$.

Second tool: Observational check list to assess school environment which adopted by the United States environmental protection agency, (2014) and adapted by the investigator. It comprised two main parts consisted of safety measures and sanitation filled by the investigator during school visits. The two parts consisted of 22 items covering school building, playground area, kitchen, classrooms, and school health clinics.

Scoring system: Each item scored (1) if available and scored (zero) if not available. The total score of environmental assessment was considered sanitary if the score was $80 \%$ or more and insanitary if less than $80 \%$.

Validity and Reliability of tool: The validity of the tool was tested by jury of 5 experts from Community Health Nursing department Faculty of Nursing of Benha University, who review the tool for content validity. Also they were asked to judge the items for completeness and clarity and suggestion were considered. The reliability of the tool was 
done using cronbach"salpha reliability

\section{Ethical consideration:}

All relevant ethical aspects were considered before starting the study for ensuring the team members' privacy and confidentiality of the collected data throughout the study and include : The purpose of the study was explained before applying the tools to gain team members confidence and trust to participate in the study .Oral consent to participate in the current study was taken after the purpose of the study was explained each team member and voluntary participation as, right to refuse and withdraw at any time without explanation.

\section{Pilot study:}

The pilot study was carried out on $10 \%$ of the sample (29) members who were selected from the three mentioned schools in Benha City. Those members were included in the actual study. The pilot study was done to assess the tool feasibility, applicability and time needed to fill each sheet. The data obtained from the pilot study was analyzed. Accordingly, modification needed were made such as, omission, addition and rewording.

\section{Field Work:}

Approval of school manager obtained through an official permission and oral consent took from each school team member. The analysis which equals 0.83 .

investigator introduced her and explained the purpose of the study, the collection of data conducted by the investigator using the study tools for team members in the selected schools through period of six months. The actual fieldwork started from beginning of April, 2019 to the end of September, 2019. The investigator went to each school from selected school 2 days per week from 8:00 am to $12: 00 \mathrm{pm}$. About (4-6) members per day were interviewed with the investigator. The investigator observed the school environment.

\section{Statistical analysis:}

The collected data was analyzed, tabulated and presented in figures using the number and percentage distribution, mean and stander deviation using statistical analysis package for social science (SPSS) version 20. Data were presented using proper statistical tests that were used to determine whether there significant relation or not and if there were positive correlation or not. The following statistical tests that were used: Number and Percentage: Mean and stander deviation (SD) and Chi-square $\mathrm{X}^{2}$ was used for qualitative data. Also P-value was used to determine significance of results as follows $:<0.05$ is statistically significant difference: $>0.05$ not statistically significant difference and $<0.01$ it is highly significant difference. 


\section{Results}

Table (1): Shows that, $50.2 \%$ of the studied team members aged from 35-45 years with mean age $42.8 \pm 42.22$ years. As regarded sex $58.1 \%$ of them were female, also $55.5 \%$ of them had university education, Regarding to occupation, $65.5 \%$ of school team members were teachers. also $40.5 \%$ of them had more than 20 years of experience in the field work. Regarding income, $68.5 \%$ of school team members' income was inadequate. As regarding $78.2 \%$ of them not attending training courses related first aids.

Table (2): Shows that $63.3 \%, 71.3 \%, 62.6 \%$ of the studied school team members had complete correct knowledge regarding disability meaning, disability types and disability causes respectively.

Table (3): Displays that $36.7 \%$ of studied team members had incomplete correct knowledge about injuries meaning. $46.4 \%$ of them had complete correct knowledge about exposure range to injuries and39.8\%about injuries causes. $75.1 \%$ of them had incomplete correct knowledge about relation between disability type and injury type.71.6\% of them had no knowledge about pace where injury most likely occur
Table (4): Represents that;47\%, 55\% of studied school team members had correct knowledge about electrical shock and suffocation, receptively. Also 38.8\%, 52.2\%, 46. $4 \%$ of them had incomplete correct knowledge about wounds, burns and and poisoning, receptively. While $38 \%$ of studied team members had no knowledge about falling.

Table (5): Shows that there were highly statistically significant relation between studied school team members total knowledge and their personal characteristics (age, sex, educational level, experience years, family income, training courses and job).

Table (6): Shows that there were highly statistically significant relation between studied school team members total practices and their personal characteristics (age, sex, educational level, experience years, family income, training courses and job).

Table (7): There were positive correlation between studied school team members total knowledge and their total practices regarding injury 
Table (1): Distribution of studied team members regarding personal characteristics $(n=289)$.

\begin{tabular}{|c|c|c|}
\hline Demographic characteristics & No & $\%$ \\
\hline \multicolumn{3}{|l|}{ Research setting } \\
\hline Al-Fikria school & 106 & 36.7 \\
\hline AL-Amal school & 101 & 34.9 \\
\hline EL-Nour school & 82 & 28.4 \\
\hline \multicolumn{3}{|l|}{ Age/ years } \\
\hline$<35$ & 53 & 18.3 \\
\hline $35-$ & 145 & 50.2 \\
\hline $45+$ & 91 & 31.5 \\
\hline Mean \pm SD & \multicolumn{2}{|c|}{$42.8 \pm 42.22$} \\
\hline \multicolumn{3}{|l|}{ Education level } \\
\hline Read and write & 16 & 5.5 \\
\hline Basic Education & 34 & 11.7 \\
\hline Secondary education & 79 & 27.2 \\
\hline University education & 161 & 55.5 \\
\hline \multicolumn{3}{|l|}{ Job } \\
\hline Teacher & 189 & 65.5 \\
\hline Specialist(socialnutrition- & 46 & 15.9 \\
\hline Clean workers & 35 & 12.1 \\
\hline Security man & 19 & 6.5 \\
\hline \multicolumn{3}{|l|}{ Experience years } \\
\hline$<10$ & 77 & 26.6 \\
\hline $10-$ & 95 & 32.9 \\
\hline$>20$ years & 117 & 40.5 \\
\hline \multicolumn{3}{|l|}{ Family income } \\
\hline Adequate & 91 & 31.5 \\
\hline Inadequate & 198 & 68.5 \\
\hline \multicolumn{3}{|l|}{ Training courses } \\
\hline Yes & 63 & 21.8 \\
\hline No & 226 & 78.2 \\
\hline
\end{tabular}

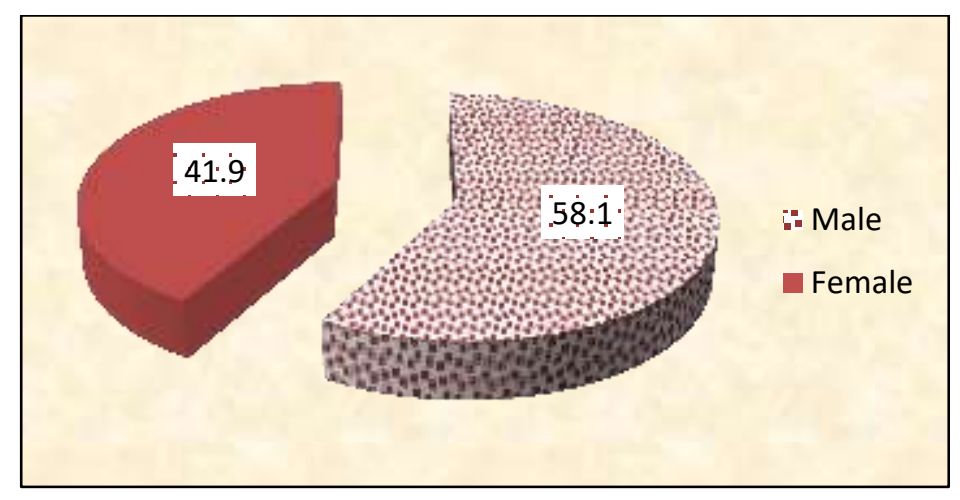


Mona Mostafa Mohamed, Hanaa Abd-Elgawad Abd-Elmegeed and Doaa Sobhy Mohamed Elsayed

Figure (1): Percentage distribution of studied school team members regarding their sex

$$
(\mathbf{n = 2 8 9})
$$

Table (2): Distribution of studied school team members' knowledge about disability (n=289).

\begin{tabular}{|l|l|l|l|l|l|l|}
\hline \multirow{2}{*}{ Knowledge } & \multicolumn{2}{l}{ Complete Correct } & \multicolumn{2}{l|}{ Incomplete Correct } & \multicolumn{2}{l|}{ Don't know } \\
\cline { 2 - 7 } & No & $\%$ & No & $\%$ & No & $\%$ \\
\hline Disability meaning & 183 & 63.3 & 25 & 8.7 & 81 & 28.0 \\
\hline Disability types & 206 & 71.3 & 21 & 7.3 & 62 & 21.5 \\
\hline Disability causes & 181 & 62.6 & 18 & 6.2 & 90 & 31.1 \\
\hline
\end{tabular}

Table (3): Frequency distribution of studied school team members regarding knowledge about injuries among disabled children $(n=289)$

\begin{tabular}{||l|l|l|l|l|l|l|}
\hline \multicolumn{1}{|c|}{ Knowledge } & \multicolumn{2}{l|}{$\begin{array}{l}\text { Complete } \\
\text { Correct }\end{array}$} & \multicolumn{2}{l|}{$\begin{array}{l}\text { Incomplete } \\
\text { Correct }\end{array}$} & \multicolumn{2}{l|}{ Don't know } \\
\cline { 2 - 8 } & No & $\%$ & No & $\%$ & No & $\%$ \\
\hline Injuries meaning & 106 & 36.7 & 93 & 32.2 & 90 & 31.1 \\
\hline Most exposure sex for injuries & 134 & 46.4 & 127 & 43.9 & 28 & 9.7 \\
\hline Injuries exposure causes & 115 & 39.8 & 109 & 37.7 & 65 & 22.5 \\
\hline $\begin{array}{l}\text { Relation between disability type } \\
\text { and injury type }\end{array}$ & 70 & 24.2 & 217 & 75.1 & 2 & .7 \\
\hline $\begin{array}{l}\text { Places where injuries occur most } \\
\text { likely }\end{array}$ & 23 & 8.0 & 59 & 20.4 & 207 & 71.6 \\
\hline Types of injuries & 59 & 20.4 & 104 & 36.0 & 126 & 43.6 \\
\hline
\end{tabular}

Table (4): Frequency distribution of studied school team members regarding their total knowledge regarding preventive measures among disabled children $(n=289)$

\begin{tabular}{|l|l|l|l|l|l|l||}
\hline \multirow{2}{*}{ Total knowledge } & \multicolumn{2}{l}{$\begin{array}{l}\text { Complete } \\
\text { Correct }\end{array}$} & \multicolumn{2}{l|}{$\begin{array}{l}\text { Incomplete } \\
\text { Correct }\end{array}$} & \multicolumn{2}{l||}{ Don't know } \\
\cline { 2 - 7 } & No & $\%$ & No & $\%$ & No & $\%$ \\
\hline Total falling & 72 & 24.9 & 102 & 35.3 & 115 & 39.8 \\
\hline Total wound & 81 & 28.0 & 112 & 38.8 & 96 & 33.2 \\
\hline Total burn & 39 & 13.5 & 151 & 52.2 & 99 & 34.3 \\
\hline Total poisoning & 37 & 12.8 & 134 & 46.4 & 118 & 40.8 \\
\hline Total electrical shock & 47 & 16.3 & 130 & 45.0 & 113 & 39.1 \\
\hline
\end{tabular}




\begin{tabular}{|l|l|l|l|l|l|l|}
\hline Total suffocation & 55 & 19.0 & 104 & 36.0 & 129 & 44.6 \\
\hline
\end{tabular}

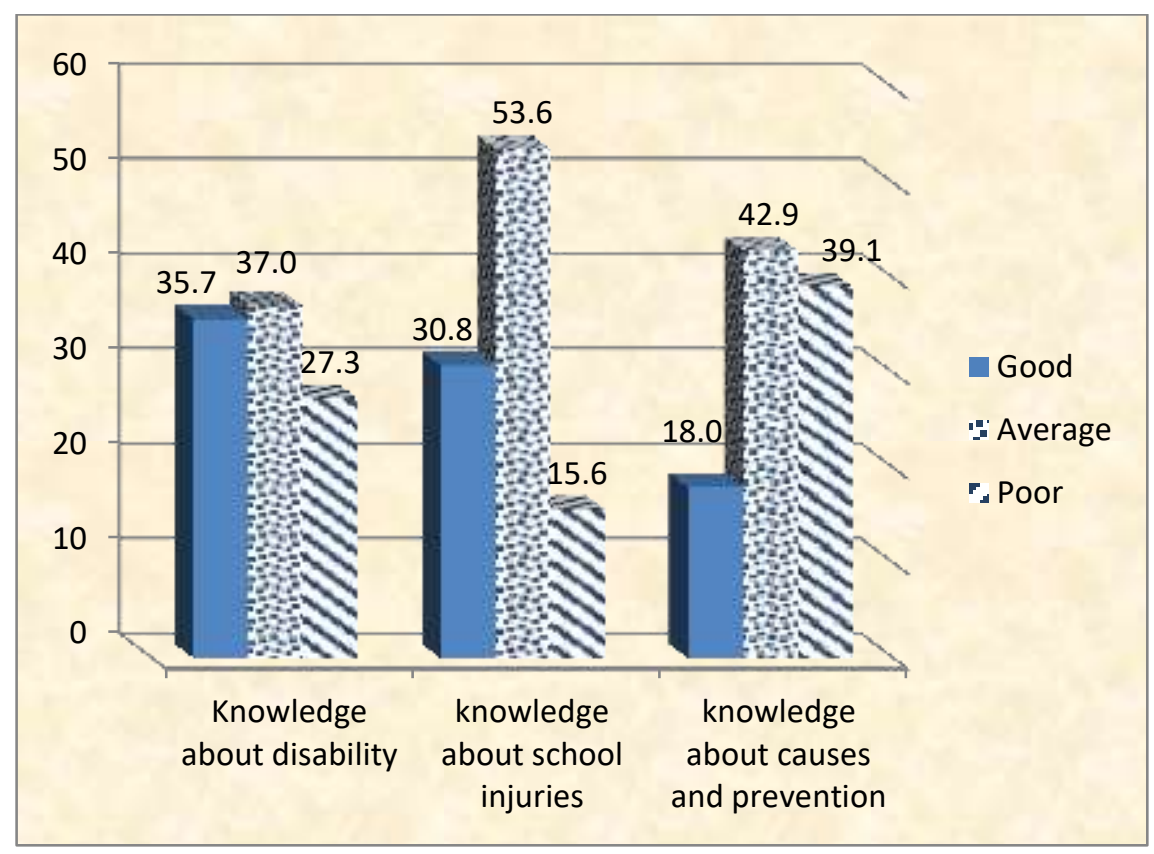

Figure (2): Percentage distribution of studied school team members regarding their knowledge about disability, injuries and preventive measures $(n=289)$

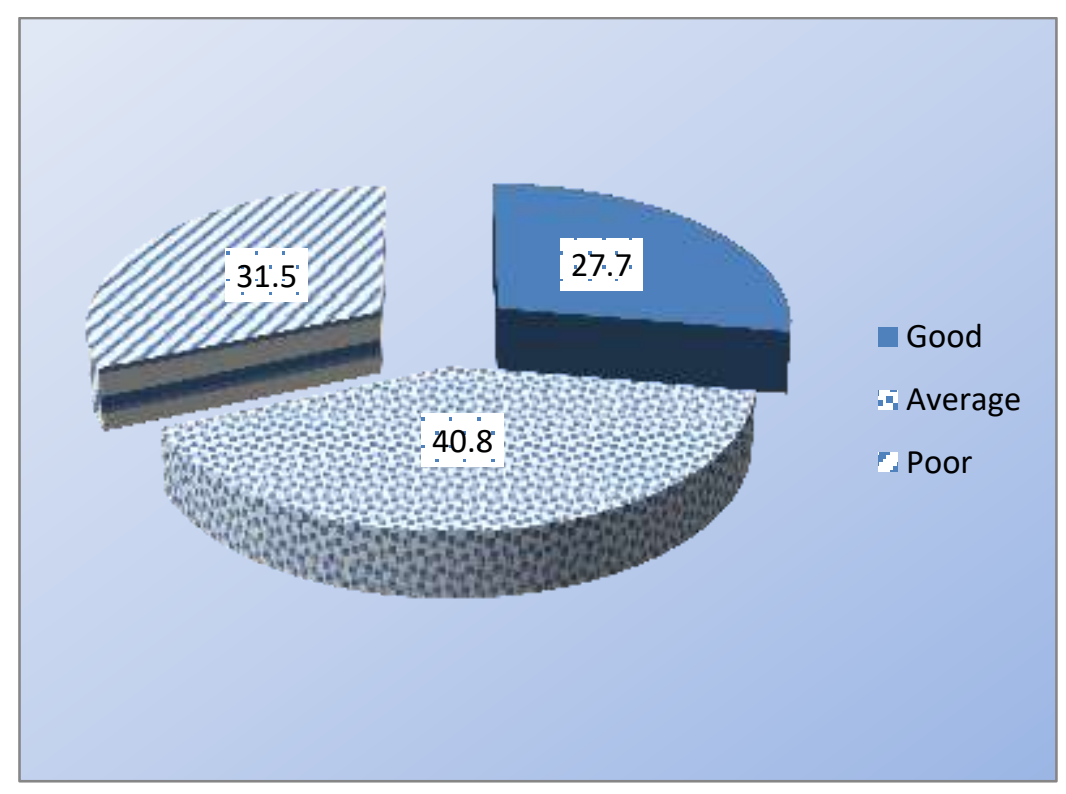

Figure (3): Percentage distribution of studied school team members regarding their total knowledge about disability and injuries $(\mathbf{n}=\mathbf{2 8 9})$ 


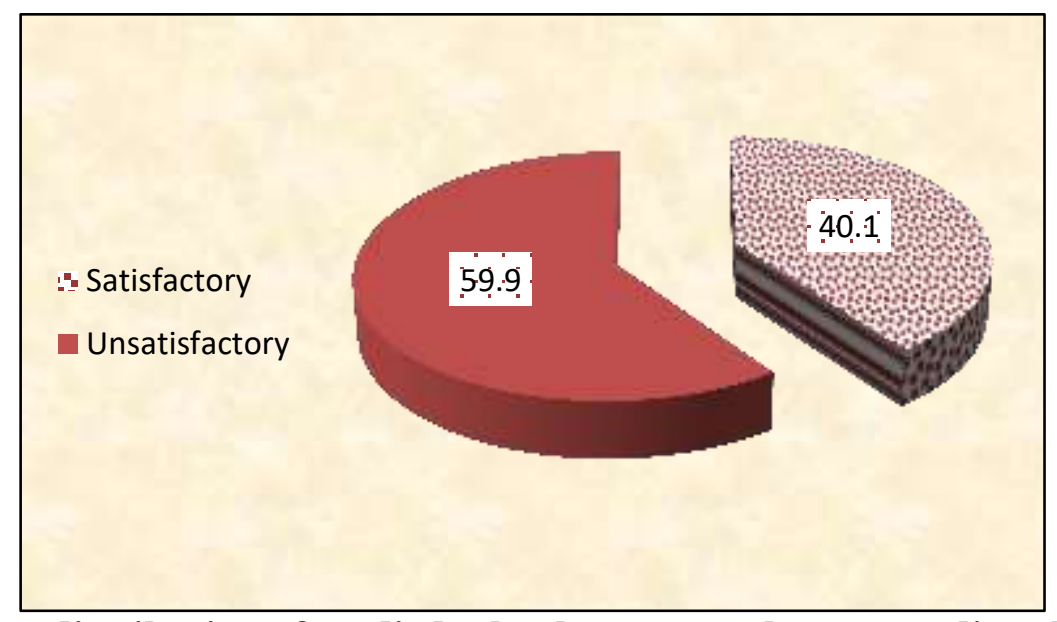

Figure (4): Percentage distribution of studied school team members regarding their reported practices regarding first aid of injuries to disabled children $(\mathbf{n}=\mathbf{2 8 9})$.

Table (5): Statistical relation between studied team members total knowledge and their personal characteristics.

\begin{tabular}{|c|c|c|c|c|c|c|c|c|}
\hline \multirow[t]{2}{*}{ Items } & \multicolumn{2}{|c|}{ Poor $(n=91)$} & \multicolumn{2}{|c|}{ Average } & \multicolumn{2}{|c|}{ Good $(n=80)$} & \multirow[t]{2}{*}{$\mathbf{X}^{2}$} & \multirow[t]{2}{*}{ p-value } \\
\hline & $\mathrm{No}$ & $\%$ & $\mathrm{No}$ & $\%$ & No & $\%$ & & \\
\hline \multicolumn{9}{|l|}{ Age/ years } \\
\hline$<35$ & 48 & 52.7 & 3 & 2.5 & 2 & 2.5 & 140.2 & $0.000^{* *}$ \\
\hline $35-$ & 29 & 31.9 & 87 & 73.7 & 29 & 36.3 & & \\
\hline $45+$ & 14 & 15.4 & 28 & 23.7 & 49 & 61.3 & & \\
\hline \multicolumn{9}{|l|}{ Sex } \\
\hline Male & 77 & 84.6 & 30 & 25.4 & 14 & 17.5 & 100.9 & $0.000 * *$ \\
\hline Female & 14 & 15.4 & 88 & 74.6 & 66 & 82.5 & & \\
\hline \multicolumn{9}{|l|}{ Education level } \\
\hline Read and write & 12 & 13.2 & 0 & 0.0 & 3 & 3.8 & 106.22 & $0.000^{* *}$ \\
\hline Basic Education & 26 & 28.6 & 3 & 2.5 & 5 & 6.3 & & \\
\hline Secondary education & 40 & 44.0 & 28 & 23.7 & 11 & 13.8 & & \\
\hline University education & 13 & 14.3 & 87 & 73.7 & 61 & 76.3 & & \\
\hline \multicolumn{9}{|l|}{ Experience years } \\
\hline$<10$ years & 6 & 6.6 & 18 & 15.3 & 53 & 66.3 & 237.2 & $0.000 * *$ \\
\hline 10-20 years & 78 & 85.7 & 14 & 11.9 & 3 & 3.8 & & \\
\hline$>10$ years & 7 & 7.7 & 86 & 72.9 & 24 & 30.0 & & \\
\hline \multicolumn{9}{|l|}{ Family income } \\
\hline Adequate & 13 & 14.3 & 28 & 23.7 & 50 & 62.5 & 51.4 & $0.000^{* *}$ \\
\hline Inadequate & 78 & 85.7 & 90 & 76.3 & 30 & 37.5 & & \\
\hline \multicolumn{9}{|l|}{ Training courses } \\
\hline Yes & 54 & 59.3 & 3 & 2.5 & 6 & 7.5 & 110.4 & $0.000 * *$ \\
\hline No & 37 & 40.7 & 115 & 97.5 & 74 & 92.5 & & \\
\hline \multicolumn{9}{|l|}{ Job } \\
\hline Teacher & 78 & 85.7 & 86 & 72.9 & 26 & 32.5 & 120.8 & $0.000 * *$ \\
\hline Specialist(social & 13 & 14.3 & 23 & 19.5 & 10 & 12.5 & & \\
\hline
\end{tabular}


Knowledge and Practices of School Team Members Regarding Injuries Prevention among Disabled Children

\begin{tabular}{||l|l|l|l|l|l|l|l|l||}
\hline Clean workers & 0 & 0.0 & 0 & 0.0 & 34 & 42.5 & & \\
\hline Security man & 0 & 0.0 & 9 & 7.6 & 10 & 12.5 & & \\
\hline
\end{tabular}

Table (6) Statistical relation between studied school team members total practices and their personal characteristics

\begin{tabular}{|c|c|c|c|c|c|c|}
\hline \multirow[t]{2}{*}{ Items } & \multicolumn{2}{|c|}{$\begin{array}{l}\text { Unsatisfactory } \\
(n=173)\end{array}$} & \multicolumn{2}{|c|}{ Satisfactory $(n=116)$} & \multirow[t]{2}{*}{$\mathbf{X} 2$} & \multirow[t]{2}{*}{ p-value } \\
\hline & No & $\%$ & No & $\%$ & & \\
\hline \multicolumn{7}{|l|}{ Age/ years } \\
\hline$<35$ & 51 & 29.5 & 2 & 1.7 & 68.6 & $0.000 * *$ \\
\hline $35-$ & 96 & 55.5 & 49 & 42.2 & & \\
\hline$>45$ & 26 & 15.0 & 65 & 56.0 & & \\
\hline \multicolumn{7}{|l|}{ Sex } \\
\hline Male & 118 & 68.2 & 3 & 2.6 & 122.8 & $\mathbf{0 . 0 0 0 * * *}$ \\
\hline Female & 55 & 31.8 & 113 & 97.4 & & \\
\hline \multicolumn{7}{|l|}{ Education level } \\
\hline Read and write & 12 & 6.9 & 3 & 2.6 & 122.6 & $\mathbf{0 . 0 0 0 * *}$ \\
\hline Basic Education & 31 & $\mathbf{1 7 . 9}$ & 3 & 2.6 & & \\
\hline Secondary education & 79 & 45.7 & $\mathbf{0}$ & $\mathbf{0 . 0}$ & & \\
\hline University education & 51 & 29.5 & 110 & 94.8 & & \\
\hline \multicolumn{7}{|l|}{ Experience years } \\
\hline$<10$ & 25 & 14.5 & 52 & 44.8 & 89.2 & $0.000 * *$ \\
\hline $10-$ & 93 & 53.8 & 2 & 1.7 & & \\
\hline$>10$ & 55 & 31.8 & 62 & 53.4 & & \\
\hline \multicolumn{7}{|l|}{ Family income } \\
\hline Adequate & 25 & 14.5 & 66 & 56.9 & 57.9 & $0.000^{* *}$ \\
\hline Inadequate & 148 & 85.5 & 50 & 43.1 & & \\
\hline \multicolumn{7}{|l|}{ Training course } \\
\hline Yes & 58 & 33.5 & 5 & 4.3 & 34.7 & $0.000 * *$ \\
\hline No & 115 & 66.5 & 111 & 95.7 & & \\
\hline Job & & $\mathbf{0 . 0}$ & & $\mathbf{0 . 0}$ & & \\
\hline Teacher & 144 & 83.2 & 46 & 39.7 & 73.8 & $0.000 * *$ \\
\hline Specialist(social & 11 & 6.4 & 35 & 30.2 & & \\
\hline Clean workers & 18 & 10.4 & 16 & 13.8 & & \\
\hline Security man & $\mathbf{0}$ & $\mathbf{0 . 0}$ & 19 & $16 . S 4$ & & \\
\hline
\end{tabular}

Table ( 7 ) Correlation between total knowledge and total practices of school team members regarding injury prevention among disabled children.

\begin{tabular}{|l|l|l|}
\hline \multirow{2}{*}{ Items } & Total knowledge & \\
\cline { 2 - 3 } & R & p-value \\
\hline Total practices & 0.12 & $0.03^{*}$ \\
\hline
\end{tabular}




\section{Discussion}

Concerning the personal characteristics of school team members the findings of the current study revealed that half of school team members' age ranged between 35-45years. More than half of them were females and had university education. These results were in agreement with Banerji (2015) who studied "Preventing unintentional injuries in children and youth in Canadian schools "and stated that the majority of teachers were females and more than half of them had university education.

Regarding to occupation less than two thirds of school team members were teachers and more than one third of them had years of experience for more than 20 years. Regarding to income, more than half of them their income was inadequate. These results were in agreement with Banerji (2015) that the majority of school team members were teachers and had more than 20 years of experience.

Regarding to school team members' first aids training, the majority of them didn't receive any first-aid training courses before. This was consistent with Li et al., (2014) who studied "Pediatric first aid knowledge and attitudes among staff in the preschools of Shanghai, China" and stated that, more than two thirds of the studied sample had not taken any first-aid training courses before. Also this was consistent with Öztürk et al., (2017) who studied "Home accident and mothers' measurements in preschool children in Izmir, Turkey" and stated that less than one third of the mothers had taken first aid training; and more than two thirds of them had not. This result might be related to that ministry of education in Egypt focused on courses which related to teaching only and this study will recommend conducting first-aid training courses at schools.

Concerning team members knowledge regarding disability. The present study revealed that more than half of school team members had complete knowledge regarding disability meaning, disability types and disability causes. This result agreed with AbdElazim, (2017) who studied " School team member' awareness regarding injury prevention among disabled children "and reported that two thirds of school team members had complete knowledge regarding disability meaning, disability types and disability causes. This results might be related to that the majority of school team members were teachers and highly education so they know more information about disability.

Concerning team members' knowledge regarding injuries of disabled children the present study revealed that about one third of school team members had complete knowledge about injuries meaning. This result agreed withParveen, (2017) who studied "Assessment of the status of injury knowledge prevention and management at various levels of sports persons" and reported that $35 \%$ of sports persons had complete knowledge about injuries meaning. This result may be due to school team members had long experience and information about injuries that occurs to disabled children due to frequent interaction between them and disabled children.

Concerning team members knowledge regarding the most injuries exposure sex the present study revealed that more than one third of school team members had complete knowledge about the most injuries exposure sex. This result disagreed with Eldeeb et al., (2014) who studied "Prevalence of disabilities 
among preschool children in one selected village of Benisuif Governorate" and reported that three quarters of preschool mothers had no knowledge about the most injuries exposure sex.

Concerning to causes of injuries among disabled children (table3) the present study showed that about one third of school members had complete knowledge about causes of injuries exposure. This result in agreement with Aly et al., (2015) who studied "Effect of disability on physical growth of primary school children in Assiut city" and reported that $37 \%$ of school children had complete knowledge about causes of injuries exposure.

According to relation between types of disability and injuries among disabled children the present study showed that more than three quarters of school team members had incomplete knowledge about the relation between disability type and the injury type. This result was in disagreement with Frank, (2016) who studied "Disability and accident occurrence among primary disabled school children in Barcelona city, Spain" and stated that more than half of disabled children had complete knowledge about the relation between disability type and the injury type.

Regarding to the most frequent places for injuries the present study showed that more than half of school members didn't know the common places of injuries. This study agreed with Thein et al., (2016) who studied" knowledge, attitude and practices of childhood injuries and their prevention by primary caregivers in Singapore" and reported that $56 \%$ of caregivers didn't know the common places of injuries.

Concerning the most types of injuries occurs to disabled children (table 3 ) about one third of school members had incomplete knowledge regarding types of injuries. This was contradicted with Saragiotto et al., (2014) who studied "Risk factors and injury prevention in elite athletes: a descriptive study of the opinions of physical therapists, doctors and trainers " and stated that two thirds of them had complete knowledge regarding types of injuries.

Concerning the total level of school team members' knowledge regarding injury prevention the present study revealed that one third of school members had good total knowledge about disability, more than half of them had average knowledge about school injuries and more than one third had average total knowledge about causes and prevent methods of injuries. This result was disagreed with AbdElazim, (2017) who studied " School team member' awareness regarding injury prevention among disabled children "and reported that the majority of school team members had poor total knowledge regarding disability and school injuries.

Regarding to the causes of electrical shock, more than one third of school team members had incomplete knowledge about causes of electrical burn. About half of school team members didn't know prevention of burn. This result go in the same line with Jahanpour, (2018) who studied " Mothers' knowledge, attitudes, and performance toward household accidents at home in children 1-5 years old: An intervention study" and reported that one third of mothers had incomplete knowledge about causes of electrical burns.

Regarding to causes of poisoning, about half of school team members had incomplete knowledge about causes of poisoning. This was in disagreement with Alazab (2015) who study "Determinants of 
Acute Poisoning among Children (1-60) months old at a Poisoning Unit of a University Hospital, Egypt" and reported that $75 \%$ of the nurses in the hospital had complete knowledge about causes of poisoning.

Concerning to prevention of poisoning about half of school members didn't know prevention of poisoning. This was in agreement with Sobhy et al., (2014) who reported that less than one quarter of mothers didn't know prevention of poisoning.

In concern to the causes of suffocation more than three quarters of school members had complete knowledge about causes of suffocation. Regarding to prevention of suffocation more than one third had incomplete correct knowledge .these findings were in agreement with the results of Jahanpour , (2018) who stated that $80 \%$ of mothers had complete knowledge about causes of suffocation and 39\% of them had incomplete knowledge about prevention of suffocation.

Concerning the total level of school team members' knowledge regarding injury prevention the present study revealed that one third of school members had good total knowledge about disability, more than half of them had average knowledge about school injuries and more than one third had average total knowledge about causes and prevent methods of injuries. This result disagreed with AbdElazim, (2017) who studied " School team member' awareness regarding injury prevention among disabled children "and reported that the majority of school team members had poor total knowledge regarding disability and school injuries.
The present study revealed that more than half of school team members had un satisfactory practices regarding first aid. This finding was contradicted with Ramiz, (2015) who studied" knowledge, attitude and practice of caregivers regarding accident prevention for mentally disabled children, Ain Shams, Egypt" reported that the majority of the caregivers had total satisfactory practices regarding injuries first aids. This may be due to the majority of school team members didn't receive first aid courses.

Regarding relation between total knowledge and personal characteristics current study revealed that there was highly significant relation between age, sex, educational level, experience years family income, occupation and courses of first aids and total knowledge. This agreed with Thein et al. (2017) who stated that educational attainment clearly is a predictor of the mother's correct knowledge and practice on childhood injury prevention. Thus, a mother with secondary education was one and half times more likely to possess the correct knowledge than a mother with primary education or no education. A mother with tertiary education was 1.7 times more likely to possess the correct knowledge than a mother with primary or no education. Also the previous result of this study was consistent with Sobhy et al., (2014) who stated that total mother's knowledge scores were higher with increased level of education and there is a highly statistical significant difference at $(\mathrm{P}<0.001)$.. This findings were consistent with Thein et al., (2017) who stated that the higher the years of experience of school members, the more likely to possess knowledge about injuries as causes, risk factors, complication and prevention of injuries. This was contradicted with Li et al., (2017) who stated that younger employees scored higher 
knowledge, which may be already been exposed to newer knowledge regarding first aid.

The present study reported that there was a highly significant association between the school team member's total practices regarding first aids and personal characteristics). This finding was agreed with Ardelean (2017) who reported that there was a strong relation between caregivers' demographic characteristics and good practices regarding first aid measures.

The present study showed that there was a highly statistically significant association was found between total knowledge and total practice. This finding was agreed with Ardelean (2017) who reported that there was a significant association between total knowledge and total practice regarding first aids.

\section{Conclusion}

The majority of school team members had poor knowledge and practices regarding injury prevention among disabled children. Highly Statistically significant associations were found between school team members' age, sex and years of experience and their total level of knowledge. Highly significant associations were found between level of education and their total level of knowledge. Highly significant association was found between the school team member's knowledge and their practices of first aids, also statistically significant association was found between team members' total practices and their personal characteristics

\section{Recommendations}

1- Providing regular school safety and first aid training program for all school team members working at schools of disabled children and continues Training programs to students and their parents according to their disabilities.

2- Implement health and safety education curricula and instruction that help school team members develop their knowledge and practices which needed to adopt and maintain safe lifestyles.

3- Disseminate handouts to school team members about first aids of injuries.

4- More researches about effect of injury prevention training program for disabled school children on their knowledge, attitude and practice.

\section{References}

American Nurses Association (ANA), (2018): National Association of School Nurses (NASN). School nursing: Scope and standards of practice (2nd Ed.). Silver Spring, MD: Nursebooks.org.

Allender J., Rector C., and Warner K.,
(2015):Community Health $\quad$ Nursing; Promoting and Protecting the Public's Health, (7th Ed.). Promoting and Protecting the Health of Aggregates with Developmental Needs; Unintentional Injuries. Lippincott Williams \& Wilkins. Unit (6) pp; 696-967.

Alazab R., (2015): Determinants of Acute Poisoning among Children (1-60) months old at a Poisoning Unit of a University Hospital, Egypt, are Employed Mothers a Risk Factor? Retrospective Cohort Study. Journal of American Science, 8(9):1107-1116.

AbdElazem, A., (2017): School Team Member's Awareness Regarding Injury Prevention Among Disable Children. Theses, Ain Shams University, pp; 65-71. 
Aly S., Abd El-Motagally K., Ibrahim H., and EIMaghraby N., (2015): Effect of Disability on Physical Growth of Primary School Children in Assiut City. Master thesis in community health nursing. Faculty of nursing, Assiut University.

ArdeleanM, (2017): In book: INTERNATIONAL CHILDREN RIGHTS CONGRESS ( pp.500-508 ) Edition: 1Chapter: Education for Children with Special Needs Publisher: ANKARA TURKEY Editors: OZGE PINARCIK MIRAY OZOZEN DANACI

Banerji A., (2015): Preventing unintentional injuries in Indigenous children and youth in Canada. Pediatric Child Health, 17(7):393398

Eldeeb A., Abdel sadik B., and Meabed M., (2014): Prevalence of Disabilities among preschool children in one selected village of Beni-suif Governorate. Life Science Journal, 9(4):3924-3930.

Fayed F\& Darren.(2017), Family-peer linkages for children with intellectual developmental psychology 52:203-211 available at Doi :10,1016j,appdev2017,08,001

Fekaris N., Miller-Hall S., and Selekman J., (2017): Environmental Health Concerns in the School Setting. Available at www.nasn.org.

Frank. , (2016): "Disability and accident occurrence among primary disabled school children in Barcelona city, Spain

Li F., Jiang F., Jin X., Qiu Y., and Xiaoming S., (2014): Pediatric first aid knowledge and attitudes among staff in the preschools of Shanghai, China.BMC Pediatrics, 12 (1):121.

Lee L., Harrington R., Chang J., and Connors S., (2013): Increased risk of injury in children with developmental disabilities. Res DevDisabil, 29(3):247255.

New Mexico School Health Manual (NMSHM), (2015): Coordinated school health program. Implementing, the school health program. Section I, pp. 1-8. http://www.nmschoolhealthmanual.org/

Nguyen, V. (2015):Mechanisms of delayed wound healing in various models of human diseases. Journal of Human health and pathology; 9(1):123.

ÖZTÜRK C., SARI H., BEKTAŞ M., and ELÇİGíL A., (2017): Home accident and mothers measurements.

Parveen,A. (2017):Assessment of the status of injury knowledge prevention and management at various levels of sports persons. International Journal of Physiology, Nutrition and Physical Education; 2(1): 78.

Saragiotto, B., Di Pierro, C. and Lopes, A. (2014): Risk factors and injury prevention in elite athletes: a descriptive study of the opinions of physical therapists, doctors and trainers. Braz J Phys Ther.;18(2):137-143. doi:10.1590/s1413-35552012005000147 
معلومات وممارسات أعضاء الفريق المدرسي تجاه منع الإصابات للأطفال ذوى الاحتياجات الخاصة منى مصطفى محم- هناء هبدالجواد عبدالمجيد - دعاء محم صبحي

الإعاقة هي عبارة عن مصطلح يشمل العجز و القيود على النشاط وقيود المشاركة مع الاخرين في الحياة اليومية

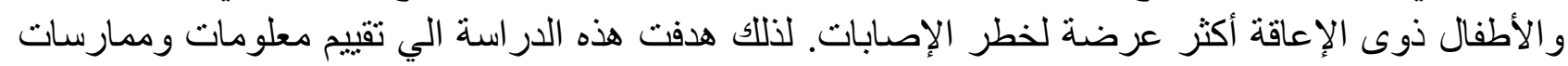

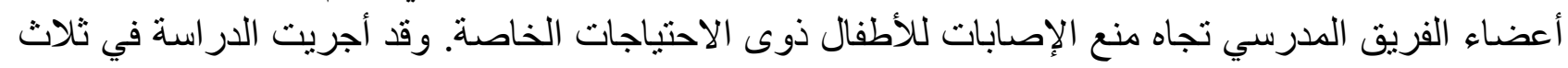

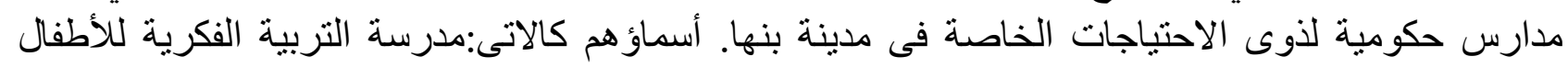

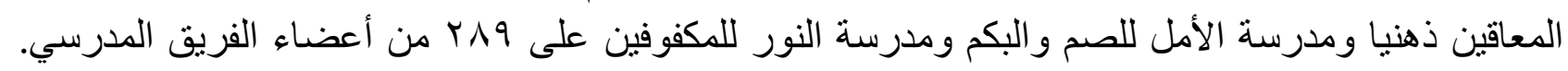

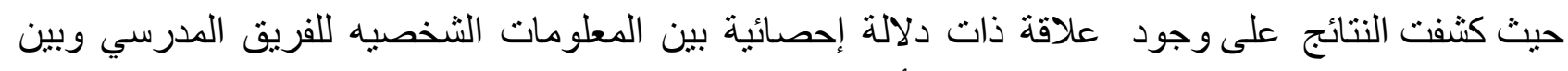

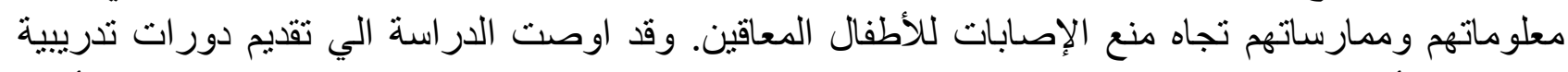

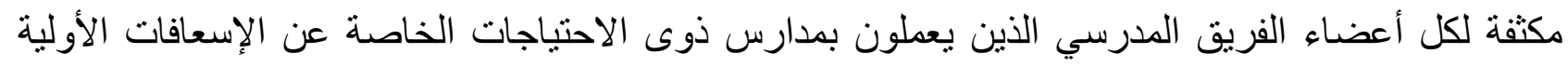
للإصابات. 